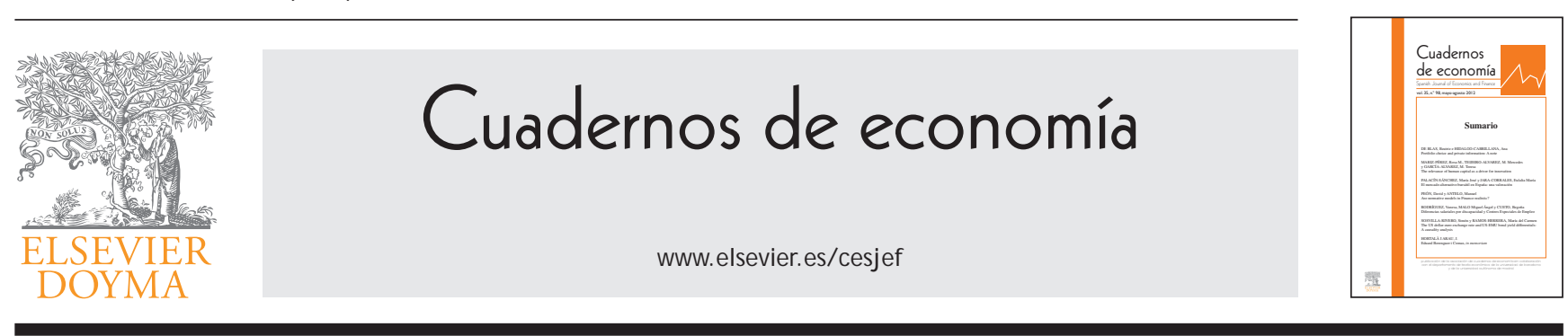

IN MEMORIAM

\title{
Eduard Berenguer i Comas, in memoriam
}

\author{
Había empezado a caminar \\ y paso a paso, avanzaba. \\ De repente el relámpago tronó \\ y la senda esperanzada \\ la luz del todo perdió. \\ Pese, empero, la sentida pérdida \\ el recuerdo perdurará.
}

Eduard Berenguer i Comas nació en Palma de Mallorca a principios de 1947 y murió repentinamente en la ciudad de Barcelona el mes de febrero de 2012. El Departamento de Teoría Económica de la Facultad de Economía y Empresa de la Universidad de Barcelona pierde a uno de sus miembros emblemáticos y más abnegados.

Estudió en la capital balear y en el año 1966 obtuvo el título de Profesor Mercantil, trasladándose a continuación a Barcelona donde se licenció en la Facultad de Ciencias Económicas y Empresariales en 1973 y siete años más tarde obtuvo el grado de Doctor con la máxima calificación.

Tuve la satisfacción de dirigir su trabajo doctoral. Un trabaj o importante y pionero sobre el uso de los modelos dinámicos de control en economía. Previamente ya había ingresado como miembro del Departamento de Teoría Económica, impartiendo clases en la licenciatura y comenzando una senda de investigación con atención preferente en cuestiones de tipo macroeconómico que pronto tendría como resultado la publicación en el año 1977 de un trabajo en Cuadernos de Economía, revista de la que sería un colaborador asiduo así como un miembro destacado de su Consejo Editorial.

En su tesis doctoral, después de plantear una revisión de los conceptos básicos de la teoría de control, elaboró con un grado elevado de formulismo una aportación original del sistema sencillo planteado por el profesor A. W. Phillips. Eran aquellos momentos en que el interés giraba alrededor de la planificación, económica y de sus implicaciones y que, más allá de la circunstancia ideológica, Berenguer se esforzó en presentar la cuestión en su alcance operativo. Al mismo tiempo quiso rendir homenaje al «inventor de la curva», para poner énfasis en su aportación sobre la teoría dinámica de la estabilización económica, comparativamente poco reconocida.
Con el título de doctor bajo el brazo, orientó su esfuerzo para acceder a la Cátedra. Desde el año 1974 que ingresó como profesor ayudante, luego como profesor adjunto interino y después de una estancia de post-grado en la Universidad de York, en el año 1984 ganó por oposición la plaza de titular de universidad y cinco años después la cátedra de Teoría Económica. El destino fue la Universidad de Extremadura, que en una recién estrenada Facultad de Económicas organizó de manera eficiente el departamento relativo a esta materia que incluía, además, la propia de Econometría. Obviamente, ejerció como Director del Departamento y también como Vice-decano de la Facultad. La siembra daría buen fruto que recogerían sus colaboradores y posteriormente colegas, J ulián Ramaj o y J uan Vega.

Mientras tanto, en el marco de su interés remarcable por la macroeconomía, publicó diferentes trabaj os sobre la función de consumo, la preferencia por la liquidez y el rol de los tipos de cambio en los países en vías de desarrollo, trabaj os publicados, además de en Cuadernos de Economía, en Información Comercial Española y en Papeles de Economía Española. Y todo ello, con el bagaje de una docencia continuada y puntual, le sirvió para opositar nuevamente, obteniendo en este caso la plaza de la Facultad de Barcelona, su Facultad, en el transcurso de una reñida oposición que concluyó en el mes de agosto de 1991.

El retorno del Dr. Berenguer a su casa fijó definitivamente su línea vital y académica. Su interés era la familia y la Facultad. No le interesaron otras opciones que se le ofrecían tanto en el mundo profesional como en el político. Comentaba que ya se lo plantearía más adelante, si fuese el caso.

La familia la formó en el año 80 al casarse en el Monasterio de Poblet con Teresa Hurtado i Margalef, que perfeccionaría más adelante al adoptar a Nicolau, nacido en Kostroma. Su dedicación familiar y sobre todo paternal fue ej emplar en todo momento, de la misma manera que lo fue su esfuerzo por la docencia. Su principal atributo, como él se atrevía a presumir, era ejercer de profesor, aunque no le dolían prendas en afirmar que escribía mejor que hablaba.

Dirigió el Departamento de Teoría Económica de la Facultad de Barcelona y al acabar las engorrosas tareas burocráticas que ello comportaba y en un período en que conseguimos el reconocimiento como profesores titulares 
de los doctores Elisenda Paluzie, Concepció Patxot, Ramon Tremosa, J oan Gil i J oan Costa, recondujo su orientación investigadora en dos temas para él primordiales, la política fiscal y la economía de la salud, con aportaciones valiosas y que no dejaría de interesarse hasta que estalló la crisis en el otoño de 2007 que entonces, de manera tan resuelta como pionera, se adentró en el mundo proceloso de la teoría económica de las finanzas. En el ínterin ejercía durante los períodos estivales como profesor invitado en la Universidad mej icana de Veracruz desde 1996 hasta el año 2006.

Por lo que respecta a los aspectos propios de la Política Fiscal, elaboró diferentes trabaj os personalmente y en colaboración con los colegas A. Manresa y C. A. Kam, que se materializaron con publicaciones en Papeles de Economía española, en EC Tax Review y European Economic Review y también con capítulos en libros especializados. En esta etapa, dedicó buena parte de su tiempo a orientar y a dirigir diferentes tesis doctorales, entre las que destacó la de la profesora Mercè Carreras que versaba sobre la problemática de la vivienda.

En relación con investigaciones concernientes a Economía de la Salud, la dedicación, el esfuerzo y la profundidad que dedicó a ello el profesor Berenguer fue remarcable. De hecho, destacó como introductor en los temas relativos a la Contabilidad Generacional, con aportaciones sugestivas que se concretaron en capítulos de diferentes libros especializados en el ámbito internacional y con un artículo valioso publicado en Investigaciones Económicas en colaboración con la profesora Gemma Abió. El reconocimiento obtenido en el ámbito de estos estudios llevó al profesor Berenguer a ejercer de consultor en diferentes organismos y particularmente ante la Comisión Permanente del Pacto de Toledo sobre la Reforma del Sistema de Pensiones.

La tercera y más reciente orientación intelectual se concretó, como he remarcado, en el ámbito de las finanzas a partir de la grave crisis económica que conmueve a la economía mundial. Entrado el otoño del año 2007 y justo el comienzo de los escándalos de las subprimes, Berenguer empezó como pionero genuino a explicar con aire divulgador la complicada naturaleza de los nuevos productos surgidos de la ingeniería financiera. Sus artículos, principalmente en La Vanguardia, clarificarían al público en general al alcance y los efectos de toda esta serie de contratos estructurados. Esta labor pedagógica tuvo como soporte la publicación de notables aportaciones en el sí del mundo académico con artículos aparecidos, cómo no, en Cuadernos de Economía, ediciones especializadas de centros de investigación del país y en la serie monográfica Economic and $\mathrm{Fi}$ nantial Papers de la Bolsa de Barcelona (BME).

Esta dedicación convirtió al Dr. Berenguer en un experto apreciado y fue reclamado para formar parte como miembro del Consejo de Administración de Empresas de Servicio e Inversión y relevantemente del Comité del Íbex-35, encargado de establecer de manera periódica las compañías que conforman este índice. Fue también requerido por el Banco Central de Kazaj stán en el verano de 2008 para impartir un seminario sobre esta materia. Más todavía: fruto de la reputación obtenida en este campo conj untamente con el grueso de sus conocimientos exhibidos en los otros cultivos de la ciencia económica, se le nombró Asesor independiente del Consell Nacional d'Unió Democràtica de Catalunya.

En fin... El Dr. Berenguer nos ha dejado. Nos ha dejado un hombre bueno, dedicado a la familia y a su hijo. Ejerció como economista competente, priorizando la docencia sin dejar de lado la investigación. Fue amigo de sus amigos y discípulo agradecido, conducta poco usual en los tiempos que corren. Descansa en paz Eduard. Te echaremos de menos.

J oan Hortalà i Arau Barcelona, abril de 2012 